\title{
CAPÍTULO 19: FARINHAS DE RESÍDUOS DA FILETAGEM DE TILÁPIA COM SABOR
}

\section{CHAPTER 19: FLOURS OF TILAPIA FILLING WASTE WITH FLAVOR}

\author{
Melina Franco Coradini ${ }^{1}$; Stefane Santos ${ }^{2}$; Gislaine Oliveira ${ }^{3}$; Isabela Julio Iwassa ${ }^{4}$; Maria Luiza \\ Rodrigues de Souza ${ }^{5}$
}

\begin{abstract}
Resumo
O objetivo do trabalho foi elaborar farinhas a partir de carcaças de tilápia, adicionando sabores, além de avaliá-las quanto aos seus aspectos físico-químicos e microbiológicos. Para a elaboração das farinhas as carcaças foram, lavadas, cozidas, prensadas, moídas e desidratadas. A partir da farinha padrão de tilápia foram produzidas as farinhas salgada e doce, totalizando três tratamentos. A farinha padrão apresentou o maior teor de proteico e de minerais, 55,39 e $28,12 \%$ respectivamente. Enquanto, que a farinha salgada de tilápia apresentou o maior teor de lipídios totais, 7,47\%, além de uma maior porcentagem de ácidos graxos ômega-3 na fração lipídica $1,14 \%$. O pH da farinha padrão de tilápia foi próximo da 7,06, porém não houve contaminação microbiológica do produto, estando todas as farinhas aptas para o consumo. Conclui-se que a farinha de tilápia padrão é a mais indicada para a inclusão em produtos alimentícios, onde o objetivo seja o aumento do teor proteico e de minerais, entretanto, analisando a fração lipídica a farinha salgada de tilápia é a mais indicada.
\end{abstract}

Palavras-Chaves: Ácidos graxos, Carcaça, Oreochromis niloticus, Pescado, Proteína.

\begin{abstract}
The objective of the work was to prepare flours from tilapia carcasses, adding flavors, in addition to evaluating them in terms of their physical-chemical and microbiological aspects. The carcasses were prepared for washing the flours, washed, cooked, pressed, ground and dehydrated. Salty and sweet flours were produced from standard tilapia flour, totaling three treatments. The standard flour had the highest protein and mineral content, 55.39 and $28.12 \%$ respectively. Whereas, the salted tilapia flour had the highest total lipid content, $7.47 \%$, in addition to a higher percentage of omega-3 fatty acids in the $1.14 \%$ lipid fraction. The $\mathrm{pH}$ of the standard tilapia flour was close to 7.06, but there was no microbiological contamination of the product, with all the flours suitable for consumption. It is concluded that the standard tilapia flour is the most suitable for inclusion in food products, where the objective is to increase the protein and mineral content, however, analyzing the lipid fraction, the tilapia salted flour is the most indicated.
\end{abstract}

Keywords: Carcass, Fatty acids, Fish, Oreochromis niloticus, Protein.

\section{Introdução}

Em 2016, a produção aquícola mundial foi de 110,2 milhões de toneladas, do total produzido pela aquicultura, 80 milhões de toneladas, foram de pescado destinados para a

\footnotetext{
${ }^{1}$ Pós-graduação em Zootecnia, Universidade Estadual de Maringá, melinacoradini@gmail.com

2 Pós-graduação em Zootecnia, Universidade Estadual de Maringá, stefane.pescap@ gmail.com

${ }^{3}$ Pós-graduação em Zootecnia, Universidade Estadual de Maringá, gislaine_oliveira14@ @otmail.com

${ }^{4}$ Pós-graduação em Engenharia Química, Universidade Estadual de Maringá, isa_iwassa@ @otmail.com

${ }^{5}$ Professora, Universidade Estadual de Maringá, mlrsouza.uem@gmail.com
} 
produção de alimentos (FAO, 2018). Entre todas as espécies de peixes a tilápia é a mais cultivada no Brasil, além disso, ela é o peixe mais introduzido e cosmopolita do mundo, presente em mais de 140 países, devido principalmente as suas características de alta adaptabilidade a produtividade (BEZERRA \& ANGELINI, 2016).

O consumo da carne de pescado é impulsionado pelo seu valor nutritivo, textura da carne e fatores relacionados aos métodos de captura, beneficiamento e processamento. Observar as formas de como o pescado, incluindo a tilápia, é beneficiados e os produtos que são elaborados a partir dele é de extrema importância para a definição das qualidades nutricionais, microbiológicas e os rendimentos do mesmo. Outro aspecto que deve se observado é sua forma de comercialização, no caso da tilápia, é majoritariamente em filés (BOSCOLO \& FEIDEN, 2007; GONÇALVES, 2011).

Da massa total do peixe o filé chega a até 40\% (SOUZA \& MACEDO-VIEGAS, 2001), portanto, há um elevado percentual de resíduos gerados durante o processamento da tilápia. Entre os resíduos estão as cabeças e vísceras que correspondem a 36\%, o espinhaço com nadadeiras (carcaça) que chegam a $22 \%$, as aparas com $3 \%$ e as peles que variam entre 8 e $10 \%$ do total do peso ao abate da tilápia (SILVA et al., 2016).

Paralelo a grande quantidade de resíduos e subprodutos gerados no processamento da tilápia do Nilo, há também a qualidade dessa matéria-prima, pois o valor nutricional desse material é de significativa importância, e quando coletado de forma adequada dentro da unidade de beneficiamento, o mesmo, pode ser destinado para a alimentação humana. Souza et al (2017) relataram que a farinha de tilápia do Nilo elaborada apenas com o espinhaço e a carne remanescente do processo de filetagem, apresenta teores médios de 51,13\% de proteína bruta, 5,82\% de lipídios totais e 37,66\% de cinzas, sendo que desses até 9,37\% são de Cálcio. Franco et al. (2013), relataram ainda, que as peles de tilápia do Nilo in natura, podem apresentar até $29,08 \%$ de proteína bruta, isso exemplifica o grande potencial nutricional desses subprodutos da indústria pesqueira.

A farinha de peixe geralmente é elaborada de forma padrão, sem a adição de ingredientes que promovam a inclusão de sabores para esse produto, diversos trabalhos já foram realizados com a utilização de farinhas de pescado em alimentos, tanto doces, quanto salgados (VERDI et al., 2020; VITORINO et al., 2020; Franco et al., 2013), porém a adição de sabor na farinha de peixe não é usual, além de ser um fator com grande potencial para a melhora da qualidade sensorial e dependendo do ingrediente utilizado, até nutricional dos produtos.

O objetivo do trabalho foi elaborar farinhas a partir de carcaças, resíduos do processo de filetagem da tilápia, com formulações salgado e doce, além de avaliá-las em relação aos seus 
aspectos físico-químicos e microbiológicos.

\section{Material e Métodos}

As farinhas foram produzidas no laboratório de tecnologia do pescado na fazenda experimental de Iguatemi (FEI), pertencente à Universidade Estadual de Maringá (UEM). O resíduo utilizado, remanescente da filetagem do peixe, foi a carcaça sem a cabeça, a pele e as vísceras, para elaboração das farinhas de tilápia (Oreochromis niloticus). A matéria-prima foi proveniente da empresa Smart-Fish (Rolândia/PR), o material foi transportado em caixas isotérmicas a uma temperatura de $0^{\circ} \mathrm{C}$ e congeladas a $-18^{\circ} \mathrm{C}$ até o momento da fabricação do produto.

Para a obtenção da farinha de tilápia, utilizaram as carcaças (espinhaço e carne remanescentes do processo de filetagem), retirando as nadadeiras, cauda, resquícios de pele e de partes aderentes dos sistemas gastrintestinais, reprodutor e rins. Após o preparo das matériasprimas, utilizou-se $5 \mathrm{~kg}$ de carcaça já limpa para a produção de cada tratamento com três repetições cada.

A metodologia para a obtenção da farinha de carcaça de tilápia, padrão (sem sabor), foi a mesma que a descrita por Souza et al. (2017), onde o material foi lavado, pesado, sanitizado com $0,1 \mathrm{mg} / \mathrm{Kg}$ de peroxitane ${ }^{\circledR} 1512 \mathrm{AL}$ e submetido ao cozimento em panela de pressão com antioxidante $(0,5 \mathrm{mg} / \mathrm{kg}$ de BHT, antioxidante), por 60 minutos. Após foi realizada a prensagem em prensa hidráulica com capacidade de 10 toneladas, para as retiradas do excesso de água e gordura, e as carcaças foram moídas em moedor de carne (modelo CAF-10). As massas obtidas foram desidratadas em estufa de secagem de ar forçada a $60^{\circ} \mathrm{C}$, por 24 horas. Após o produto desidratado o mesmo foi triturado e novamente moído em moinho tipo faca (Willye - modelo TE-650), por fim, a farinha foi embalada a vácuo e armazenada em freezer até o momento das análises e da adição dos sabores.

A partir da farinha de carcaça de tilápia padrão (sem sabor), foram produzidas farinhas de tilápia salgada e doce resultando, portanto, em três tratamentos, tratamento $1=$ farinha de tilápia natural, tratamento $2=$ farinha salgada de tilápia e tratamento $3=$ farinha doce de tilápia, os ingredientes utilizados para a adição de sabor no produto estão descritos na Tabela 1. 
Tabela 1. Ingredientes e as quantidades utilizadas na elaboração das farinhas salgada e doce de tilápia.

\section{Ingredientes}

Quantidade (g)

\begin{tabular}{lc}
\hline Farinha salgada de tilápia & \\
\hline Farinha de carcaça de tilápia (padrão) & 200 \\
Gergelim & 33 \\
Óleo de gergelim & 6 \\
Glutamato sódico & 1 \\
Sal & 3 \\
Nori & 10 \\
Molho fermentado de soja & 7,5 \\
Orégano & 1 \\
Alho em pó desidratado & 1 \\
Cebola e salsa desidratadas & 20 \\
Linhaça & 50 \\
\hline Farinha doce de tilápia & 200 \\
\hline Farinha de carcaça de tilápia (padrão) & 150 \\
Açúcar mascavo & 1 \\
Orégano & 20 \\
Canela em pó & 50 \\
Cacau em pó & 1 \\
Cravo de índia em pó & 15 \\
Gengibre em pó & 9 \\
Baunilha & 100 \\
\hline
\end{tabular}

Na elaboração da farinha salgada, a base de farinha de carcaça de tilápia (padrão) foi misturada com óleo de gergelim e molho fermentado de soja em um recipiente em placa de aquecimento a $150{ }^{\circ} \mathrm{C}$, onde se obteve uma massa homogênea, posteriormente todos os ingredientes desidratados (Tabela 1) foram adicionados ao recipiente, que permaneceu na mesma temperatura, durante 10 minutos, sempre em movimentação com uma colher de pau, para não queimar. Já para o preparo da farinha doce, foi adicionado o orégano na água, em função das suas propriedades antioxidantes e após três minutos de fervura, ele foi adicionado a farinha de carcaça de tilápia (padrão) e o açúcar mascavo. Após a massa estar bem homogeneizada, adicionaram-se ao processo os demais ingredientes (Tabela 1), deixando por 
10 minutos em cozimento na placa de aquecimento em uma temperatura de $150^{\circ} \mathrm{C}$. A massa obtida foi para a estufa a $60^{\circ} \mathrm{c}$ por $24 \mathrm{~h}$, depois foi moída em um moedor tipo faca (Willye modelo TE-650). Após o resfriamento das farinhas elas foram embaladas e acondicionadas a uma temperatura de $-18^{\circ} \mathrm{C}$ até o momento das análises físico-químicas e microbiológicas.

A análise de composição química foi realizada no LANA - Laboratório de Alimentos e Nutrição Animal da Universidade Estadual de Maringá. Para a determinação dos teores de umidade, cinzas e a quantificação dos minerais cálcio e fósforo, as análises foram realizadas seguindo a metodologia da AOAC (2005). Os teores de proteína bruta foram avaliados pelo método de semimicro Kjeldahl (SILVA \& QUEIROZ, 2002) e para a extração dos lipídios totais se empregou o método Bligh \& Dyer (1959).

O valor calórico (VC) foi determinado segundo Souci et al. (2000), obtido pela soma da multiplicação do teor de proteína bruta (PB), lipídios totais (LT) e carboidratos (CB) multiplicados pelos fatores 4,9 e 4 , respectivamente. Seguindo a fórmula: VC $(\mathrm{Kcal} / \mathrm{Kg})=$ $\mathrm{PBx} 4+\mathrm{LPx} 9+\mathrm{CBx} 4$.

O perfil de ácidos graxos foi determinado de acordo com a metodologia descrita por Hartman \& Lago (1973), aproximadamente $100 \mathrm{mg}$ de lipídios de cada tratamento foi transmetilada, usando uma solução de cloreto de amônia e ácido sulfúrico, em metanol como agente esterificante. Os ésteres de ácidos graxos foram isolados e analisados em cromatógrafo gasoso (Agilent, modelo 7890 ), acoplado a um detector de massas (Agilent 5975C), utilizando uma coluna ZB- Wax Polietileno Glicol (30 m de comprimento x 0,25 mm de diâmetro interno x $0,25 \mu \mathrm{m}$ de espessura do filme). O gás de arraste foi o Hélio (He) e o fluxo de injeção foi de 1 $\mathrm{ml} / \mathrm{min}$ Split 1:10. A temperatura inicial da coluna foi estabelecida em $50^{\circ} \mathrm{C}$, mantida por 2 minutos, sendo então elevada para $220^{\circ} \mathrm{C}$ a uma taxa de $4^{\circ} \mathrm{C} /$ min e mantida por 7 minutos. A temperatura do injetor utilizada foi de $250^{\circ} \mathrm{C}$. A identificação dos ácidos graxos foi realizada pela comparação dos tempos de retenção dos ésteres metílicos das amostras com os de padrões autênticos (Sigma).

As análises microbiológicas foram realizadas no laboratório de Microbiologia e Microscopia de Alimentos da Universidade Estadual de Maringá - UEM. Foram amostrados $100 \mathrm{~g}$ de cada tratamento, sendo analisados para o número mais provável (NMP) de Coliformes a $35^{\circ} \mathrm{C}$ e $45^{\circ} \mathrm{C}$, contagem de Staphylococcus coagulase positiva em unidade formadora de colônia (UFC)/grama e de Salmonella spp, de acordo com APHA (2001). O protocolo microbiológico seguiu os padrões recomendados pela Resolução RDC n ${ }^{\circ} 12$, de 2 de janeiro de 2001, da Agência Nacional de Vigilância Sanitária (BRASIL, 2001). 
Para a medição do $\mathrm{pH}$, foi utilizada amostra homogeneizada de farinha (10 gramas) com água destilada (1:10 amostra/água). O homogeneizado foi submetido aos eletrodos do pHmetro (DM 22, Digimed, São Paulo, Brasil) por 5 minutos, quando foi procedida a leitura do $\mathrm{pH}$. A atividade de água das amostras de cada tratamento foi determinada, utilizando o aparelho da marca Aw Sprint - Novasina TH-500.

O delineamento experimental foi inteiramente ao acaso, foi realizada uma ANOVA e os resultados significativos submetidos ao teste de Tukey a $5 \%$ de probabilidade, testando as diferenças entre os três tratamentos. Para toda a análise foi utilizado o programa SAS Inst. Inc., Cary, NC, USA (2000). Não foi realizada análise estatística para os resultados da microbiologia e do perfil de ácidos graxos.

\section{Resultados e Discussão}

São muitos os produtos que podem ser elaborados utilizando resíduos de peixes, gerados pelas indústrias beneficiadoras de pescado, entre eles a farinha de peixe é um dos mais produzidos, apesar disso, existe uma falta de padronização em relação aos valores nutricionais desse produto, sendo ele elaborado para a alimentação humana, ou para a alimentação animal (ARRUDA et al., 2006).

De acordo com os resultados da composição química e do valor calórico das farinhas de tilápia, houve diferenças significativas entre os tratamentos para todos os nutrientes avaliados (Tabela 2).

Tabela 2. Composição química, cálcio, fósforo e valor calórico de farinhas obtidas a partir de carcaça de tilápia padrão, salgada e doce.

\begin{tabular}{|c|c|c|c|c|c|}
\hline \multirow{2}{*}{$\begin{array}{l}\text { Composição } \\
\text { química (\%) }\end{array}$} & \multicolumn{3}{|c|}{ Farinhas de carcaça de tilápia } & \multirow{2}{*}{$\begin{array}{c}\text { Valor de } \\
\text { p. }\end{array}$} & \multirow{2}{*}{$\begin{array}{l}\text { C.V. } \\
(\%)\end{array}$} \\
\hline & Padrão & Salgada & Doce & & \\
\hline Umidade & $3,53 \pm 1,04^{\mathrm{b} 1}$ & $6,06 \pm 0,46^{\mathrm{a}}$ & $4,11 \pm 0,46^{\mathrm{b}}$ & $<0,0001$ & 2,10 \\
\hline Proteína & $55,39 \pm 17,23^{\mathrm{a}}$ & $26,64 \pm 11,52^{c}$ & $32,45 \pm 5,71^{b}$ & $<0,0001$ & 1,14 \\
\hline Lipídios & $4,26 \pm 0,84^{\mathrm{b}}$ & $7,47 \pm 2,37^{\mathrm{a}}$ & $3,57 \pm 1,53^{\mathrm{b}}$ & $<0,0001$ & 5,41 \\
\hline Minerais & $28,12 \pm 8,58^{\mathrm{a}}$ & $17,71 \pm 1,83^{\mathrm{b}}$ & $12,78 \pm 6,76^{\mathrm{c}}$ & $<0,0001$ & 1,43 \\
\hline Carboidratos & $0,04 \pm 29,51^{\mathrm{c}}$ & $42,04 \pm 12,49^{a}$ & $46,56 \pm 17,01^{\mathrm{a}}$ & $<0,0001$ & 1,85 \\
\hline Cálcio & $5,16 \pm 2,81^{\mathrm{a}}$ & $1,04 \pm 1,31^{\mathrm{b}}$ & $0,85 \pm 1,50^{\mathrm{b}}$ & $<0,0001$ & 9,21 \\
\hline Fósforo & $5,46 \pm 2,63^{\mathrm{a}}$ & $1,78 \pm 1,05^{\mathrm{b}}$ & $1,26 \pm 1,57^{\mathrm{bc}}$ & $<0,0001$ & 5,63 \\
\hline V.C. ${ }^{3}(\mathrm{Kcal} / 100 \mathrm{~g})$ & $260,07 \pm 56,70^{b}$ & $342,03 \pm 25,26^{\mathrm{a}}$ & $348,20 \pm 31,43^{\mathrm{a}}$ & $<0,0001$ & 1,27 \\
\hline
\end{tabular}


O teor de umidade da farinha salgada de tilápia foi o mais elevado dentre todos os tratamentos, 6,06\% (Tabela 2), porém, a concentração de umidade desse tratamento ainda é inferior a máxima estabelecida para produtos similares com origem do pescado, segundo o Regulamento da Inspeção Industrial e Sanitária de Produtos de Origem Animal (RIISPOA, 2017) esses produtos não devem conter mais que 12\% de umidade em sua composição.

A farinha padrão apresentou $55,39 \%$ de proteína em sua composição, seguida pelas farinhas doce e salgada, 32,45 e 26,64\%, respectivamente. O tratamento um também apresentou o maior teor de minerais, $28,12 \%$, seguido pelos tratamentos dois, $17,71 \%$ e três, $12,78 \%$. A diminuição desses nutrientes se deve a adição dos produtos utilizados nas farinhas salgada e doce, já que os ingredientes possuem maiores concentrações de outras frações como os carboidratos.

A utilização de ingredientes com altos teores de carboidratos nas farinhas salgada e doce fica evidente, quando se observam as suas composições, já que esses tratamentos apresentam um teor médio de 44,3\% para esse nutriente, enquanto que a farinha padrão possui um teor de $0,04 \%$, pois se trata de um produto exclusivamente de origem animal (Tabela 2).

De acordo com Souza et al. (2017) farinhas de tilápias elaboradas, também com carcaças, assim como a farinha padrão do presente trabalho, apresentaram teores médios de 1,78\% para umidade, 51,13\% para proteínas, 5,82\% para lipídios e 37,66\% para cinzas e não apresentaram carboidratos em sua composição. Os mesmos autores citam ainda uma alta concentração de cálcio e fósforo para a farinha de tilápia, 9,37 e 6,08\%, respectivamente, esses valores são superiores aos encontrados na farinha padrão de tilápia que foram de 5,16\% para cálcio e 5,46\% para fósforo.

Em relação ao teor lipídico a tilápia é um peixe que possui uma baixa fração, quando comparado a outros, o filé de tilápia cru possui 5,82\% de lipídios totais (SIMÕES et al., 2007), enquanto que o salmão chega a até 18,81\% (TONIAL et al., 2010). Em se tratando de farinhas elaboradas com essas espécies de peixes, a farinha de carcaça de salmão apresenta uma média de 9,3\% de lipídios (SOUZA et al., 2017), enquanto, que a farinha salgada de tilápia, do presente trabalho, apresentou $7,47 \%$, um teor inferior quanto comparada com a farinha da outra espécie de peixe. Entretanto, além do teor de lipídios totais, quando estuda-se sobre composição de produtos a base de pescado é importante observar também, o perfil dos ácidos graxos encontrados.

Como durante a obtenção das farinhas é natural que ocorra a lixiviação de alguns nutrientes, foram avaliados os perfis de ácidos graxos dos três tratamentos. Sendo assim, foram 
detectados um total de 25 ácidos graxos na farinha padrão, 24 ácidos graxos na farinha salgada e 23 ácidos graxos na farinha doce (Tabela 3).

Tabela 3. Perfil de ácidos graxos de farinhas obtidas a partir de carcaça de tilápia padrão, salgada e doce.

\begin{tabular}{|c|c|c|c|}
\hline Ácidos graxos (\%) & Padrão & Salgada & Doce \\
\hline Ácido Láurico C12:0 & 0,0039 & 0,0031 & 0,0046 \\
\hline Ácido Mirístico C14:0 & 0,1221 & 0,0463 & 0,0601 \\
\hline Ácido Pentadecílico C15:0 & 0,0123 & 0,0047 & 0,0062 \\
\hline Ácido Palmítico C16:0 & 0,9917 & 0,8951 & 0,8464 \\
\hline Ácido Palmitoleico C16:1(9) $\omega 7$ & 0,2357 & 0,0811 & 0,1087 \\
\hline Ácido Margárico C17:0 & 0,0178 & 0,0088 & 0,0110 \\
\hline Ácido Cis-10-hepadecanóico C17:1 & 0,0158 & 0,0078 & 0,0073 \\
\hline Ácido Esteárico C18:0 & 0,3260 & 0,4691 & 0,7158 \\
\hline Ácido Oleico C18:1(9) $\omega 9$ & 1,3857 & 2,3356 & 1,1933 \\
\hline Ácido Vacênico C18:1(11) $\omega 7$ & 0,1184 & 0,1005 & 0,0719 \\
\hline Ácido Linoleico C18:2(9,12) $\omega 6$ & 0,4480 & 2,1382 & 0,2785 \\
\hline Ácido Gama Linolênico GLA C18:3(6,9,12) $\omega 6$ & 0,0347 & 0,0105 & 0,0160 \\
\hline Ácido Alfa Linolênico C18:3(9,12,15) $\omega 3$ & 0,0297 & 1,1352 & 0,0187 \\
\hline Ácido Linoleico conjugado CLA C18:2(9,11) $\omega 6$ & 0,0085 & 0,0026 & 0,0040 \\
\hline Ácido Estearidônico C18:4(6,9,12,15) $\omega 3$ & 0,0025 & 0,0000 & 0,0000 \\
\hline Ácido Araquídico C20:0 & 0,0122 & 0,0398 & 0,0247 \\
\hline Ácido Gadoleico C20:1 $\omega 11$ & 0,0800 & 0,0370 & 0,0386 \\
\hline Ácido Eicosadienóico C20:2(11,14) $\omega 6$ & 0,0290 & 0,0105 & 0,0124 \\
\hline Ácido Di-homo-alfa-Linolênico C20:3(11,14,17) $\omega 3$ & 0,0092 & 0,0021 & 0,0040 \\
\hline Ácido Di-homo-gama-Linolênico DGLA C20:3(8,11,14) $\omega 6$ & 0,0327 & 0,0103 & 0,0000 \\
\hline Ácido Araquidônico C20:4(5,8,11,14) $\omega 6$ & 0,0719 & 0,0190 & 0,0315 \\
\hline Ácido Eicosapentaenóico EPA C20:5(5,8,11,14,17) $\omega 3$ & 0,0041 & 0,0064 & 0,0021 \\
\hline Ácido Behênico C22:0 & 0,0061 & 0,0187 & 0,0073 \\
\hline Ácido Erúcico C22:1(13) $\omega 9$ & 0,0069 & 0,0096 & 0,0026 \\
\hline Ácido Lignocérico C24:0 & 0,0072 & 0,0100 & 0,0049 \\
\hline Ácidos graxos monoinsaturados & 1,8425 & 2,5716 & 1,4224 \\
\hline Ácidos graxos poli-insaturados & 0,6703 & 3,3348 & 0,4032 \\
\hline Ácidos graxos insaturados (AGPI) & 2,5128 & 5,9064 & 1,8256 \\
\hline Ácidos graxos saturados (AGS) & 1,4993 & 1,4596 & 1,6810 \\
\hline Ômega $3(\omega 3)$ & 0,0455 & 1,1437 & 0,2480 \\
\hline
\end{tabular}




\begin{tabular}{|c|c|c|c|}
\hline Ômega $6(\omega 6)$ & 0,6248 & 2,1911 & 0,3424 \\
\hline Ômega $9(\omega 9)$ & 1,3926 & 2,3452 & 1,1959 \\
\hline Relação ômega 6/ômega 3 ( $\omega 6 / \omega 3)$ & 13,7318 & 1,9158 & 1,3806 \\
\hline Relação AGPI/AGS & 1,6760 & 4,0465 & 0,1446 \\
\hline
\end{tabular}

Entre os ácidos graxos encontrados nas diferentes farinhas de tilápia destacam-se os ácidos graxos palmítico, palmitoleico, oleico, linoleico e alfa-linolênico, entretanto, esses ácidos graxos apareceram em quantidades diferentes nos três tratamentos. Em relação aos ácidos graxos poli-insaturados eles foram encontrados em maior quantidade na farinha salgada de tilápia, o seu teor foi de 3,33 ou 44,88\%, em relação à quantidade de lipídios totais, esse valor é alto quando comparado com o relatado por Ferreira et al. (2007) para filé de tilápia cru, cujo teor relatado foi de $22,97 \%$.

A relação ômega-6/ômega-3 é utilizada para analisar o teor nutricional dos lipídios nos alimentos. O Departamento de Saúde da Inglaterra (HMSO, 1994) recomenda uma razão de no máximo 4, sendo assim, os valores encontrados nas farinha salgada e doce estão dentro do padrão estabelecido por esse órgão. Já a farinha padrão de tilápia apresentou uma relação mais alta do que a recomendada, o que é justificado pela baixa concentração de ácidos graxos da série ômega-3 presente nesse tratamento. Ferreira et al. (2007) relataram que a razão ômega6/ômega-3 do filé de tilápia do Nilo in natura foi de 6,64.

A inclusão de outros ingredientes nas farinhas salgada e doce alterou a relação ômega6/ômega-3. A linhaça, por exemplo, é rica em ácidos graxos poli-insaturados da série ômega3, como o alfa-linolênico, chegando a um teor de até $63,26 \%$, em relação à quantidade de lipídios totais dessa semente, sendo assim, a sua utilização contribuiu para o aumento desse tipo de ácido graxo (NOVELO \& POLLONIO, 2012).

O Departamento de Saúde da Inglaterra determina ainda que índices inferiores a 0,45 para a razão ácidos graxos poli-insaturados/saturados potencializam o risco de aumento do colesterol sanguíneo. A farinha doce de tilápia foi a única a apresentar um valor inferior ao recomendado, aproximadamente 0,14 , indicando que esse tratamento é o menos indicado para a prevenção deste tipo de comorbidade, já os tratamentos 1 e 2, farinhas padrão e salgada apresentaram valores superiores 1,68 e 4,05, respectivamente, estando dentro das recomendações (HMSO, 1994).

Tanto a atividade de água, quanto o $\mathrm{pH}$ das farinhas de tilápia apresentaram diferenças significativas a $5 \%$ de probabilidade. As farinhas padrão e doce apresentaram atividades de água similares, 0,19 e 0,21, respectivamente, entretanto, a farinha salgada de tilápia apresentou 
uma atividade de água superior 0,42, assim como, a maior umidade (Tabela 2), isso ocorreu provavelmente por causa da inclusão de alimentos com maiores concentrações lipídica, como o óleo de gergelim, por exemplo, já que a introdução deste tipo de ingrediente proporciona uma menor perda de água durante a segunda desidratação da farinha salgada, realizada durante a sua obtenção.

$\mathrm{O}$ pH do pescado propicia condições que estimulam a multiplicação microbiana, pois a sua carne possui um $\mathrm{pH}$ próximo a neutralidade, além de grande atividade de água (OLIVEIRA et al., 2008). Por esses e outros fatores a elaboração de produtos como farinhas proporciona um maior tempo de estocagem para esse tipo de alimento de origem animal, já se observou a cima que a com a elaboração da farinha a atividade de água obtida foi baixa, entretanto os pH 7,06 para a farinha padrão, 6,54 para a farinha salgada e 7,68 para a farinha doce é um fator relevante para a contaminação microbiana, já que estão próximos a neutralidade.

Mesmo com o pH da farinha padrão de tilapia sendo próximo a neutralidade $(7,09)$ e os demais 6,54 (salgada) e 7,68 (doce) a qualidade microbiana das farinhas de tilápia, estavam dentro dos limites exigidos pela legislação brasileira para produtos derivados do pescado (BRASIL, 2001). O Número mais Provável de Coliformes a $35^{\circ}$ e $45^{\circ}\left({ }^{1} \mathrm{NMP} / \mathrm{g}\right)$ foi menor que 3, a contagem de Estafilococos Coagulase Positiva (UFC/g) foi inferior a $1 \times 10^{2}$ e a pesquisa de Salmonella Spp. em $25 \mathrm{~g}$ de amostra foi ausente, esse resultado mostra a importância de que os resíduos de pescado destinados ao processamento se transformando em subprodutos, devem ser obtidos seguindo os critérios de Boas Práticas e Fabricação (BPF) (Tabela 4).

Tabela 4. Microbiologia de farinhas obtidas a partir de carcaça de tilápia padrão, salgada e doce.

\begin{tabular}{|c|c|c|c|c|}
\hline $\begin{array}{l}\text { Farinhas } \\
\text { de carcaça } \\
\text { de tilápia }\end{array}$ & $\begin{array}{c}\text { Coliformes } \\
\text { fecais a } 35^{\circ} \mathrm{C} \\
\left(\mathrm{NMP}^{1 / g}\right)\end{array}$ & $\begin{array}{c}\text { Coliformes } \\
\text { fecais a } 45^{\circ} \mathrm{C} \\
\left(\mathrm{NMP}^{1} / \mathrm{g}\right)\end{array}$ & $\begin{array}{c}\text { Contagem de } \\
\text { Estafilococos coagulase } \\
\text { positiva }\left(\mathrm{UFC}^{2} / \mathrm{g}\right)\end{array}$ & $\begin{array}{c}\text { Pesquisa } \\
\text { de Salmonella } \\
\text { Spp em 25g }\end{array}$ \\
\hline Natural & $<3$ & $<3$ & $1 \times 10^{2}$ & AUSENTE \\
\hline Salgada & $<3$ & $<3$ & $1 \times 10^{2}$ & AUSENTE \\
\hline Doce & $<3$ & $<3$ & $1 \times 10^{2}$ & AUSENTE \\
\hline
\end{tabular}

${ }^{1} \mathrm{NMP}=$ Número Mais Provável; ${ }^{2} \mathrm{UFC}=$ Unidade Formadora de Colônia.

Os resultados obtidos deixam clara a possibilidade do consumo das farinhas de tilápia sem e com sabor, sem riscos à saúde, quando se leva em conta a contaminação microbiológica. Isso mostra que durante a obtenção das matérias-primas, transporte, manipulação e 
processamento dos produtos, houve uma preocupação com as condições higiênico-sanitárias dos ingredientes, utensílios e ambientes utilizados.

\section{Conclusões}

Todas as farinhas estavam dentro dos padrões microbiológicos e aptas para o consumo.

A farinha de tilápia padrão é a mais indicada para a inclusão em produtos alimentícios, onde o objetivo seja o aumento do teor proteico e de minerais, entretanto, em se tratando da fração lipídica a farinha com a formulação salgada de tilápia é a mais indicada para o consumo.

\section{Referências}

APHA- AMERICAN PUBLIC HEALTH ASSOCIATION. Compendium of methods for the microbiological examination of foods. Ed. 4, Washington, DC, p. 2001. 1219, 2001.

ARRUDA, Lia Ferraz de et al. Nutritional aspects of Nile tilapia (Oreochromis niloticus) silage. Food Science and Technology, v. 26, n. 4, p. 749-753, 2006.

ASSOCIATION OF OFFICIAL ANALYTICAL CHEMISTS [AOAC]. Official methods of analyses of the association of analytical chemists (18th ed.). Gaithersburg, US, 2005.

BEZERRA, Luis Artur Valões; ANGELINI, Ronaldo. Aquicultura de tilápia no Brasil: produção ilimitada pela ciência. Boletim da Associação Brasileira de Limnologia, v. 42, p. 17-24, 2016.

BLIGH, E. G.; DYER, W. J. A rapid method of total lipid extraction and purification. Canadian Journal of Biochemistry, Ottawa, v. 37, p. 911-17, 1959.

BOSCOLO, W. R.; FEIDEN, A.; SIGNOR, A. A. Farinha de resíduos da indústria de filetagem de tilápias. Industrialização de tilápias. Toledo: GFM Gráfica \& Editora, p. 135-150, 2007.

BRASIL. Ministério da Saúde. Agência Nacional de Vigilância Sanitária. Resolução RDC n. 12, de 02 de janeiro de 2001. Regulamento Técnico sobre os padrões microbiológicos para alimentos. Disponível em: <http://portal.anvisa.gov.br/wps/wcm/connect/a47bab8047458b909541d53fbc4c6735/RDC_1 2_2 01.pdf?M OD=AJPERES>. Acesso em: 23 de maio de 2020. 
DEPARTMENT OF HEALTH COMMITTEE ON MEDICAL ASPECTS OF FOOD POLICY. Nutritional aspects of cardiovascular disease. London: HMSO, 1994.

FAO. FOOD AND AGRICULTURE ORGANIZATION OF THE UNITED NATIONS.The State of World gonFisheries and Aquaculture 2018 - Meeting the sustainable development goals. p. 7-69, 2018.

FERREIRA, Milena Wolff et al. Efeito dos métodos de cocção sobre a composição química e perfil lipídico de filés de Tilápia do Nilo (Oreochromis niloticus Linnaeus 1757). Ciência e Agrotecnologia, v. 31, n. 3, p. 798-803, 2007.

FRANCO, M.L.R.S.; ABREU, B. B.; SACOMANNI, A. P. O. ; VESCO, A. P. D. ; VIEIRA, V. I. ; MIKCHA, J. M. G.; GASPARINO, E. ; DELBEM, A.C.B. Elaboración de cookies y galletasconinclusión de harina de pescado. Infopesca Internacional, v. 53, p. 30-33, 2013.

GONÇALVES, A. A. Tecnologia do pescado: ciência, tecnologia, inovação e legislação, Editora: Ateneu, São Paulo, p. 95-99, 2011.

HARTMAN, L., \& LAGO, R.C.A. Rapid preparation of fatty acids methyl esters. Laboratory Practice, v. 22, n. 6, p. 475-476, 1973.

NOVELlo, D.; POLLONIO, M. A. R. Caracterização físico-química e microbiológica da linhaça dourada e marrom (Linum Usitatissimum L.). Rev Inst Adolfo Lutz, v 71, p. 291-300, 2012.

OLIVEIRA, N.M.S.; OLIVEIRA, W.R.M.; NASCIMENTO, L.C.S.; VICENTE, J.M.S.F; FIORINI, E.; EVANGELISTA, J.; BRESSAN, M.C. Avaliação físico-química de filés de tilápia (Oreochromis niloticus) submetidos à sanitização. Food Science and Technology, Campinas, v. 28, n.1, p. 83-89, 2008.

RIISPOA - Regulamento da Inspeção Industrial e Sanitária de Produtos de Origem animal. Ministério da Agricultura, Pecuária e Abastecimento. Seção II - Derivado do Pescado, Artigo 466, 2017.

SAS. Institute (Cary, USA). SAS/STAT Userees guide, version 6. 4.ed., Cary. v.1. 943p, 2000.

SILVA, D.J.; QUEIROZ, A.C. Análise De Alimentos: Métodos Químicos e Biológicos, Viçosa, Universidade Federal De Viçosa, Ed. 3, p. 235, 2002. 
SILVA, L. M.; SAVAY-DA-SILVA, L. K.; ABREU, J. G.; FIGUEIREDO, E. E. S. Determinação de índices morfométricos que favorecem o rendimento industrial de filés de tilápia (Oreochromis niloticus). Boletim Instituto de Pesca, v. 42, n. 1, p. 252-257, 2016.

SIMÕES, M. R.; RIBEIRO, C. F. A.; RIBEIRO, S. C. A.; PARK, K. J.; MURR, F. E. X. Composição físico-química, microbiológica e rendimento do filé de tilápia tailandesa (Oreochromis niloticus). Ciência e Tecnologia de Alimentos, v. 27, n. 3, p. 608-613, 2007.

SOUCI, S. W.; FACHMAN, H.; KRAUT, E. Foods Composition and Nutrition Tables. Medpharm Scientific Publishers, Ed. 6, 2000.

SOUZA, M.L.R.; MACEDO-VIEGAS, E.M. Comparação de quatro métodos de filetagem utilizado para a tilápia do Nilo (Oreochromis niloticus) sobre o rendimento do processamento. Infopesca Internacional, Uruguay, p.26-31, 2001.

SOUZA, M. L. R.; YOSHIDA, G. M.; VASCONCELOS, G. A.; MOURA, L. B.; XAVIER, T. O.; GOES, E. S. R. Formulation of fish waste meal for human nutrition. Acta Scientiarum: Technology, v. 39, p. 525-531, 2017.

TONIAL, I. B; OLIVEIRA D. F; BRAVO C. E.C; SOUZA N. E; MATSUSHITA M; VISENTAINER J.V. Caracterização FísicoQuímica e Perfil Lipídico do Salmão (Salmo salar L.). Rev Alim. Nutr., v. 21, p. 93-98, 2010.

VERDI, R.; GASPARINO, E.; CORADINI, M. F.; CHAMBO, A. P. S.; FEOHRMANN, A. C.; GOES, E. S. R.; SOUZA, M. L. R. Inclusion of dehydrated mix of tilapia and salmon in pizzas. Food Science and Technology, Ahead of Print, 2020.

VITORINO, K. C.; CHAMBO, A. P. S.; CORADINI, M. F.; MATIUCCI, M. A.; MICHKA, J. M. G.; GOES, E. S. R.; GONÇALVES, A. A.; SOUZA, M. L. R. Cereal Bars Flavored with Fish Protein Concentrate from Different Species. Journal of aquatic food product technology, v 29, p. 65-72, 2020. 